Pueport No.

ER-B-91-1?
U.S. Department of Fnergy

Office of Inspector General
Release Date:

August 21, 1991

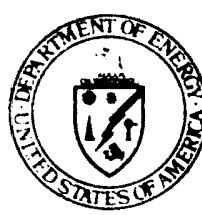

Report on

\title{
Telephone Costs At
}

Princeton Plasma Physics

Laboratory

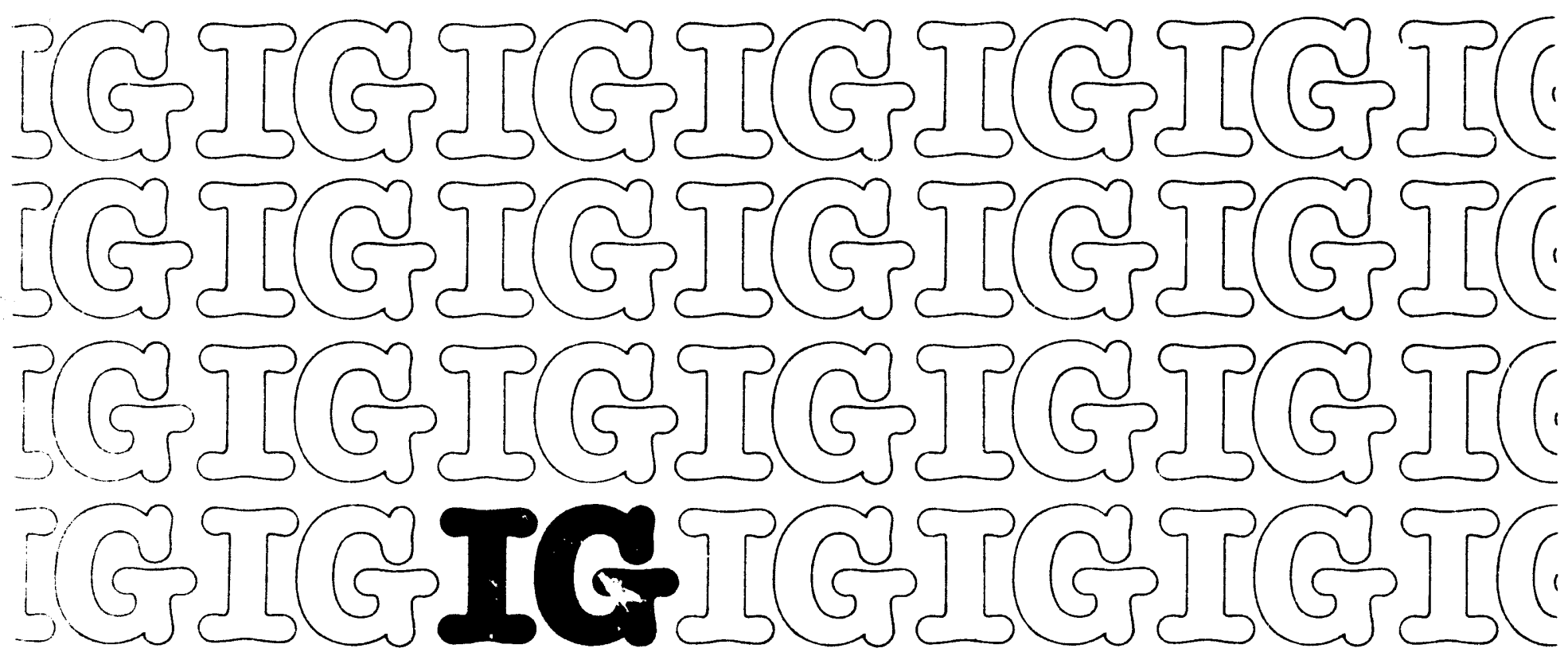


This report can be obtained from the U.S. Department of Energy

office of Scientific and Technical Information

P. O. Box 62

Oak Ridge, Tennessee 37831 
U.S. DEPARTMENT OF ENERGY OFFICE OF INSPECTOR GENERAL

ER-B--91-17

TI92 000094

TELEPHONE COSTS

AT PRINCETON PLASMA PHYSICS LABORATORY

Report No.: ER-B-91-17

Date of Issue: August 21, 1991
Eastern Regional office

oak Ridge, TN 37830

\section{MASTER}


U.S. DEPARTMENT OF ENERGY

OFFICE OF INSPECTOR GENERAL OFFICE OF AUDITS

EASTERN REGIONAL OFFICE

OAK RIDGE, TENNESSEE 37830

TELEPHONE COSTS

AT PRINCETON PLASMA PHYSICS IABORATORY

TABLE OF CONTENTS

Page

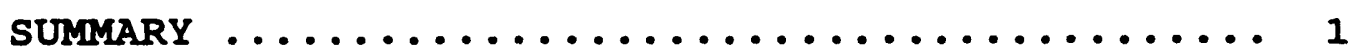

PART I - APPROACH AND OVERVIEW ................. 2

Purpose and objectives ................. 2

scope and Methodology ................. 2

Background ......................... 2

Observations and Conclusions ............. 3

PART II - FINDINGS AND RECOMMENDATIONS ..............4

1. Enforcement of Telephone

Policies and Procedures .............4

PART III - MANAGEMENT AND AUDITOR COMMENTS ........... 3 


\section{U.S. DEPARTMENT OF ENERGY \\ OFFICE OF INSPECTOR GENERAI \\ OFFICE OF AUDITS}

TELEPHONE COSTS

AT PRINCETON PLASMA PHYSICS IABORATORY

Audit Report Number: ER-B-91-17

August 21, 1991

\section{SUMMARY}

The Princeton Plasma Physics Laboratory (PPPL) is a fusion energy research laboratory located on the Forrestal Campus of Princeton University in Plainsboro, New Jersey. Princeton University operates the laboratory under contract with the U.S. Department of Energy (DOE). PPPL researches nuclear fusion and plasma physics and investigates the potential of a commercial fusion reactor. The objective of the audit was to determine whether PPPL was monitoring telephone use and costs in order to prevent personal toll costs from being charged to the DOE contract.

Our audit disclosed that 5 out of the 10 PPPL cost centers we reviewed were not following established policies and procedures for monitoring telephcne toll charges. This condition resulted because PPPL's management did not adequately review telephone use and costs. As a result, PPPL charged personal toll calls to DOE. Therefore, we recommend that the Manager, DOE Field office, Chicago, ( $\mathrm{CH}$ ) direct PPPL to enforce its telephone policies and procedures to ensure that personal toll calls are not charged to DOE.

The Acting Manager, $\mathrm{CH}$, concurred with our recommendations and agreed to implement corrective actions.

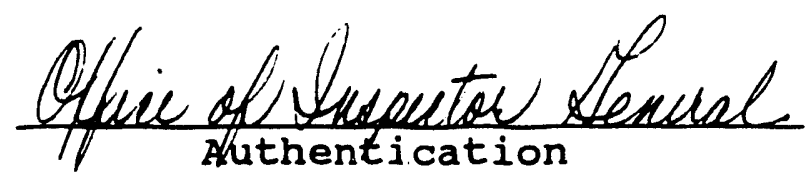




\section{PART I \\ APPROACH AND OVERVIEW}

\section{PURPOSE AND OBJECTIVES}

The purpose of the audit was to evaluate telephone costs at the Princeton Plasma Physics Laboratory (PPPL).

The objective of the audit was to determine whether PPPL was monitoring telephone use and costs in order to prevent personal telephone costs from being charged to the U.S. Department of Energy (DOE) contract.

\section{SCOPE AND METHODOLOGY}

Audit work was performed at PPPL from september 25, 1990 , through April 19, 1991, and generally covered telephone calls and costs for the period october 1, 1989, through March 20, 1991. The audit included evaluating DOE's and PPPL's telephone policies and procedures in effect at the time of the audit and verifying telephone costs.

The audit was made in accordance with generally accepted Government auditing standards for performance audits and included tests of internal controls and compliance with laws and regulations to the extent necessary to satisfy the objective of the audit.

We assessed the significant internal controls with respect to processing invoices for telephone costs and monitoring personal telephone use. Our assessment consisted of: reviewing PPPL's written policies and procedures, (2) interviewing key $D O E$ and $P P P L$ representatives to gain an understanding of PPPL's practices, (3) verifying supporting documentation, and (4) testing transactions for telephora costs and employee reimbursements for personal telephone use. Because our review was limited, it would not necessarily have disclosed all internal control deficiencies that may have existed.

DOE Field office, Chicago $(\mathrm{CH})$ representatives waived an exit conference.

\section{BACKGROUND}

PPPL is a fusion energy research laboratory located on the Forrestal Campus of Princeton University in Plainsboro, New Jersey. Princeton University operates the laboratory under 
contract $\mathrm{DE}-\mathrm{ACO} 2-76 \mathrm{CH} 03073$ administered by $\mathrm{CH}$ and the Princeton Area office. PPPL employs about 800 people on its 74-acre site. For Fiscal Year 1990, PPPL's total budget was $\$ 95$ million.

PPPL researches nuclear fusion and plasma physics and investigates the potential of the tokamak as a commercial fusion reactor. The tokamak is a circular-shaped fusion reactor with magnetic fields confining ionized gases (plasma) at extremely high temperatures. PPPL's research is centered around the operation of the Tokamak Fusion Test Reactor, a large tokamak in which an energy break-even experimental level is expected to be reached.

PPPL's telecommunication office, which reports to the manager of Information and Administrative Services, oversees all voice, data, and radio communication services. Responsibilities of the office include: (1) providing equipment and service for current and future needs, (2) overseeing system changes and maintenance, (3) processing billings for telephone costs, and (4) complying with applicable policies and procedures. The telecommunication office has three full-time employees.

PPPI has about 1,200 lines for telephones, data transmission, and facsimile machines. PPPL's telecommunication costs average about $\$ 630,000$ per year. These costs include toll calls, local message units, line charges, access charges, maintenance, repairs, and equipment rentals. Reimbursements for personal telephone calls were about $\$ 11,800$ in Fiscal Year 1990.

\section{OBSERVATIONS AND CONCLUSIONS}

PPPL generally had adequate policies and procedures to monitor, control, and minimize telephone costs. However, 5 of the 10 cost centers we reviewed were not following PPPL's procedures for monitoring telephone toll charges. As a result, PPPL charged personal toll calls to DOE. Thus, we recommend that the Manager, CH, direct PPPL to enforce its telephone policies and procedures to ensure that personal toll calls are not charged to DOE. (See Findings and Recommendations, page 4.)

our finding relating to enforcing telephone policies and procedures is a material internal control weakness that PPPL management should consider when preparing its yearend assurance memorandum on internal control. 


\title{
PART II
}

\section{EINDINGS AND RECOMMENDATIONS}

\author{
Enforcement of Telephone Policies and Procedures
}

\section{FINDING}

U. S. Department of Energy (DOE) orders and Princeton Plasma Physics Laboratory's (PPPL) policies and procedures prohibit unauthorized telephone use and require efficient and effective management of telephone resources. However, 5 of the 10 PPPL cost centers we reviewed were not following established policies and procedures for monitoring telephone toll charges. This condition resulted because PPPL's management did not adequately review telephone use and costs; specifically, (1) cost center managers did not review telephone reports and (2) the telecommunications office did not have the authority to enforce compliance with telephone policies and procedures. As a result, PPPL charged personal toll calls to DOE.

\section{RECOMMENDATIONS}

We recommend that the Manager, DOE Field office, Chicago (CH), direct PPPL to:

1. Require cost center managers to adequately review telephone use and costs;

2. Give the telecommunications office the authority to enforce compliance with telephone policies and procedures; and

3. Review telephone use and costs for the current and recent fiscal years to identify and reimburse DOE for the cost of personal toll calls charged to DOE and the cost of employee time spent on personal calls.

\section{MANAGEMENT REACTION}

The Acting Manager, $\mathrm{CH}$, concurred with our recommendations and agreed to implement corrective actions. Part III contains details 


\section{DETAILS OF FINDING}

\section{Policies and Procedures}

DOE Order 1450.3, "Authorized Use of Government Telephone Systems" dated May 26, 1988, provides PPPL guidance on policies and procedures for authorized telephone system use and personal call restrictions.

To conform to these criteria, PPPL established policies for monitoring and controlling telephone use and ninimizing costs. These policies provide that personal telephone calls be kept to a minimum and, when made, be reimbursed by the employee.

To implement these policies, PPPL established review and reimbursement procedures. Under these procedures, each cost center manager is to certify monthly, on a "verification form," that all toll calls billed to the cost center have been checked for compliance with policy. To support this certification, the procedures requize that the cost center manager should delegate a responsible individual who can verify the accuracy and reasonableness of the detailed monthly bill for each telephone line. This individual is to review the calls, mark each call as business or personal, sign the bill, and return it to the cost center manager. Upon receipt of the signed bills, the cost center manager is to list personal calls on the verification form, sign the form, and return it to PPPL's telecommunication office. The responsible employees are required to reimburse PPPL for the cost of any personal calls.

The telecommunications office is responsible for distributing the telephone bills and verification forms to each cost center. In addition, the office records and summarizes the verification forms returned by the cost center manasers.

\section{Policies and Procedures were Not Being Followed}

For 5 of the 10 PPPL cost centers we reviewed, cost center managers were not following established policies and procedures for monitoring telephone costs.

We selected for review 10 of PPPI's 56 cost centers that incurred telephone costs during Fiscal Year 1990. We judgmental selected six of these cost centers because they: (1) had large toll-call costs, and (2) represented the different types of cost centers such as administrative, scientific, and technical. We judgementally selected the four other cost centers because they had large toll-call charges during Fiscal Year 1990 but employees had made no or insignificant reimbursements for personal toll calls. 
For 5 of the 10 cost centers we reviewed, cost center managers were following procedures. However, for the other five cost centers, the cost center managers were not following policies and procedures, as they frequently signed the verification forms without receiving the monthly bills back from the employees responsible for reviewing them.

To illustrate, in one of the cost centers in which the manager did not follow procedures, there were excessive personal toll calls that had not been identified as personal. No employee in this cost center reimbursed PPPL for personal calls during Fiscal Year 1990.

For one extension we reviewed in this cost center, excessive personal toll cails were made from PPPL and from off-site locations. About 1,100 toll calls were made during Fiscal Year 1990 to the home phone of the employee to whom the extension was assigned. Often, repetitive toll calls were made from this extension to attorneys, car dealers, mortgage companies, baseball card dealers, and several other companies and individuals that were unrelated to PPPL. A telephone calling card assigned to the same employee was used in evenings, on weekends, and during vacation to make personal toll calls from off-site locations, including the employee's home and a resort area. For the 30-month period october 1988, through March 1991, (1) monthly costs for apparent personal toll calls on this extension ranged from $\$ 22$ to $\$ 108$, averaging about $\$ 60$; and (2) time per month spent on these calls during working hours ranged from 2 to 9 hours, averaging 5 hours. We estimated that this employee's time spent on personal telephone calls cost DOE an average of $\$ 150$ per month.

In addition, our review of the eight other extensions assigned to employees in this cost center disclosed examples of apparent personal toll calls to employees' homes, car dealers, hair styling salons, jewelry stores, attorneys, a landscaping company, and basebali card dealers. For instance, we found that from three extensions there were 222, 146 , and 113 toll calls, respectively, made to the employees' homes in Fiscal Year 1990.

In another cost center in which the procedures were not being followed, we found examples of personal toll calls. In this cost center, the manager signed and returned the verification forms without distributing the bills to the responsible employees and before reviewing any of the telephone charges. This cost center manager said he disregarded any phone bills under an arbitrarily selected $\$ 30$ and personally reviewed bills over $\$ 30$. This cost center reported that only one personal toll call, costing 22 cents, was made during Fiscal Year 1990. However, we scanned toll calls made from five extensions in this cost center during one month and found examples of apparent personal calls, such as toll calls to sport ticket offices, law offices, gyms, schools, and residences. 
This condition resulted because PPPL's management did not adequately review telephone use and costs. Specifically, cost center managers did not follow PPPL's procedures for reviewing telephone costs. Equally important, the telecommunications office did not have the authority to enforce compliance with telephone policies and procedures, as it could not require cost center managers to comply. Furthermore, the telecommunications office did not alert upper-level management concerning instances of noncompliance by cost center managers.

\section{Effect}

As a result, personal telephone toll calls were charged to DOE. Although we did not attempt to identify all personal calls and compute their costs, the examples described above illustrate the risk of not enforcing PPPL's policies and procedures. 
In responding to a draft version of our report, the Acting Manager, DOE Field office, Chicago ( $\mathrm{CH}$ ), concurred with our recommendations and agreed to implement corrective actions. CH's comments and our reply follows.

\section{Enforcement of Telephone Policies and Procedures}

Management comments. $\mathrm{CH}$ agreed to implement the following corrective actions in response to our three recommendations:

The Laboratory is in the process of issuing the following letters to the cost center managers:
a. A letter from the Laboratory Director directing greater management control, scrutiny, and monitoring of telephone usage and costs;
b. A letter to all employees reiterating PPPL's policy on personal use of telephones and the liability assumed by each employee for such calls.

We propose that the Telecommunications Manager report any violation of PPPL policy to an established chain of upper management and have upper management, superior to the cost center manager, enforce policy. In this manner, senior laboratory management will be aware of cost center managers that do not comply with established policy and are in a position to enforce the conformance to policy in a meaningful way.

In lieu of an audit, the results of which may or may not cover the costs of the audit itself, PPPL is proposing a one time cash settlement. We believe that this approach would be the most expeditious manner in which to settle this recommendation. The only issue to be resolved is the dollar amount of the settlement. If no settlement on the dollar amount is reached an audit will be performed. 
Auditor Comments. CH's comments are generally responsive to all recommendations in this report. If management accepts PPPL's proposed one-time cash settlement, we caution that management should review personal telephone use and costs to the extent necessary to have a basis for settlement. 

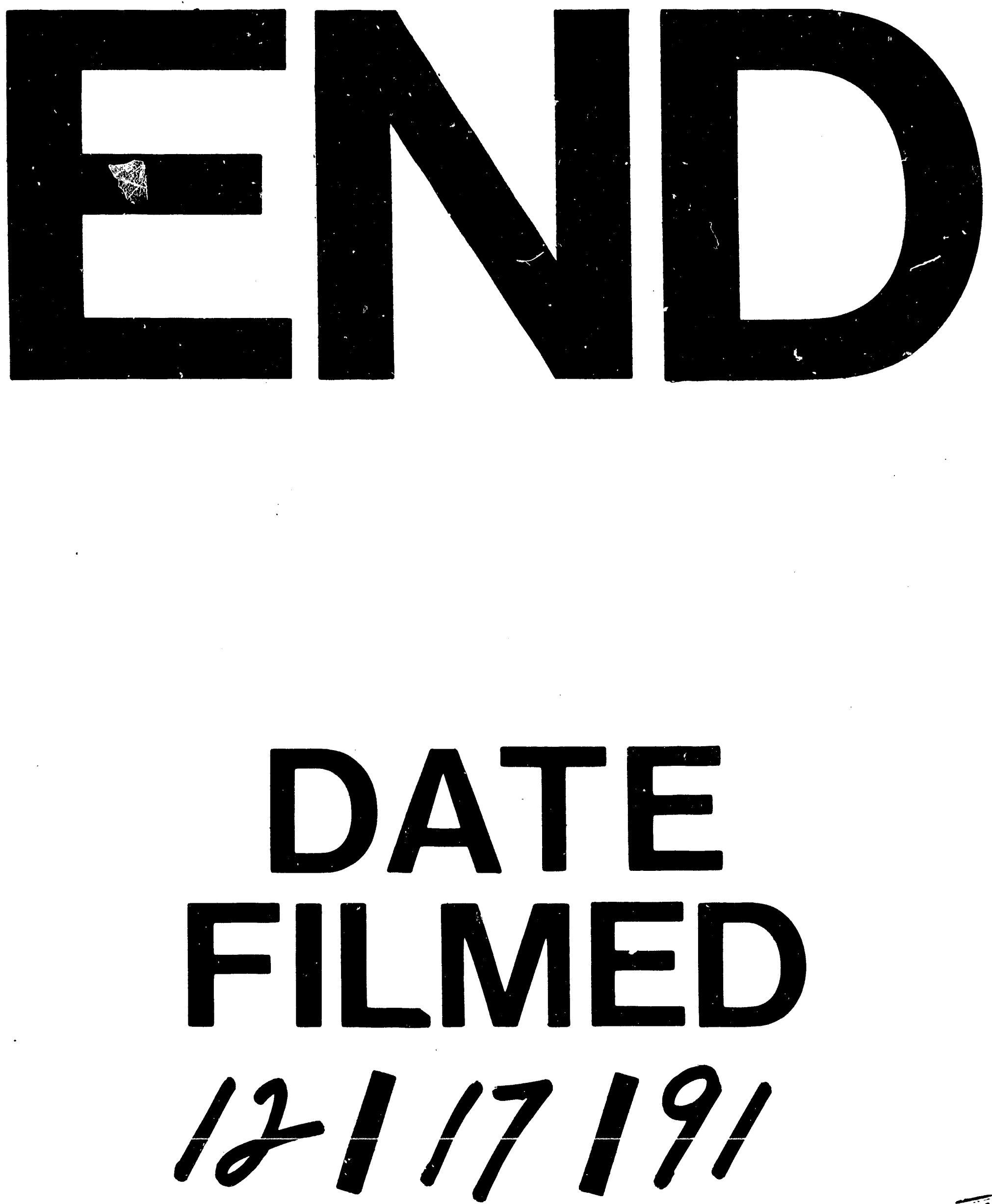

1 
